\title{
Cholelithiasis and biliary tract disease in sickle-cell disease in Nigerians
}

\author{
Olu Akinyanju \\ M.R.C.P., M.R.C.P.E. \\ FOLUSO LADAPO \\ M.B., D.M.R.D. (Eng.) \\ Departments of Medicine and Radiodiagnosis, College of Medicine and Lagos University Teaching
Hospital, Lagos
}

\begin{abstract}
Summary
The incidence of biliary tract disease was investigated by oral cholecystography and/or intravenous cholangiography in 77 unselected Nigerians with homozygous sickle-cell disease (SCD). They included 32 males and 45 females with ages ranging from 8 to 31 years. The prevalence of cholelithiasis was $9 \%$ with equal sex incidence. The stones were always multiple and $71.4 \%$ of them were radio opaque. Visualization and contractility of all gall bladders examined were normal. The only patient with symptoms and signs which suggested biliary tract disease had no radiographic evidence of cholelithiasis and it was impossible to predict the presence of cholelithiasis from the incidence of abdominal crises in the patients.

The prevalence of cholelithiasis is significantly less than that reported in American patients with SCD $(35 \%)$ and different dietary habits are probably responsible for this.
\end{abstract}

\section{Introduction}

It is well established that the prevalences of cholelithiasis and consequent biliary tract disease are unduly high and increase with age in sickle-cell disease (SCD) (Barrett-Connor, 1968; Cameron, Maddrey and Zuidema, 1971; Golding, Adeyemo and Kurtz, 1973; Ariyan, Shessei and Pickett, 1976). Although symptoms of biliary tract disease may contribute to the painful abdominal crises of SCD (Ariyan et al., 1976), the rarity of biliary tract disease in over 11 years of clinical experience with a large number of Nigerians with SCD in Lagos is impressive. Therefore it was decided to carry out this prospective study of the incidence of cholelithiasis in the SCD population.

\section{Patients and methods}

The subjects were 100 unselected consecutive Nigerians with homozygous SCD seen routinely at the adult sickle-cell clinic of the Lagos University Teaching Hospital. A total of 77 patients comprising 32 males and 45 females completed the investigations.
Their ages ranged from 8 to 31 years but $82 \%$ of them were between 10 and 21 years old. Informed consent of the patients and their parents was easily obtained. Homozygous SCD was confirmed by the presence of haemoglobin $\mathrm{S}(\mathrm{Hb} \mathrm{S})$ only, or with a typical peripheral blood-smear picture and the presence of haemoglobin S (HbS) only, or with a small amount of $\mathrm{Hb} \mathrm{F}$ on electrophoresis.

Each patient was regularly seen at least once every 3 months and a history of abdominal pains was obtained from his case note and by direct enquiry They were all physically examined for signs o. biliary tract disease before screening their galk bladders for contractile function and for choles lithiasis by plain abdominal X-ray and oral chole cystography before and after a fatty meal. Intravenous cholangiography was carried out when visualization of the gall bladder was poor after oral cholecystography. Only 7 subjects required intravenous cholangiography.

\section{Results}

The gall bladder was well visualized in all subjects and functioned normally. Gall stones were detected in 7 patients ( 3 male; 4 female) $(9 \%$ ) and $71.4 \%$ of the stones were radio opaque, and these were multiple in every case.

One boy aged 15 years had obstructive jaundice, intermittent abdominal colic and positive Murphy's sign, suggesting biliary calculi, but none was demonstrated by oral and intravenous cholecystography.

There is no consistent relationship between frequency of stones and age (Fig. 1).

Table 1 shows the proportion of patients with and without cholelithiasis who had abdominal pains in the 12 months preceding cholecystography.

\section{Discussion}

The $9 \%$ prevalence of cholelithiasis in these patients is much lower than prevalences reported in SCD in North America. Weens (1945) in a review of the literature on 44 post-mortems found that $27 \%$ 
had cholelithiasis. Even this high prevalence was underestimated as the subjects who were older than 40 years in his study had neither cholelithiasis nor anaemia and therefore might have been, as he pointed out, cases of sickle-cell trait rather than of sickle-cell disease. Barrett-Connor (1968) found cholelithiasis in $34 \%$ of 47 patients, but this prevalence was also the minimum estimate as the cholelithiasis status of 25 of them was unknown. Cameron et al. (1971) found gall stones in $41 \%$ of 46 patients who had biliary tract investigations, while Golding et al. (1973) found them in $37 \%$ of 35 patients. The overall prevalence in these 172 American patients is $35 \%$. The difference in prevalence in these Americans and in patients in this study is highly significant $\left(\chi^{2}=\right.$ 17.99; $P<0.001$ ).

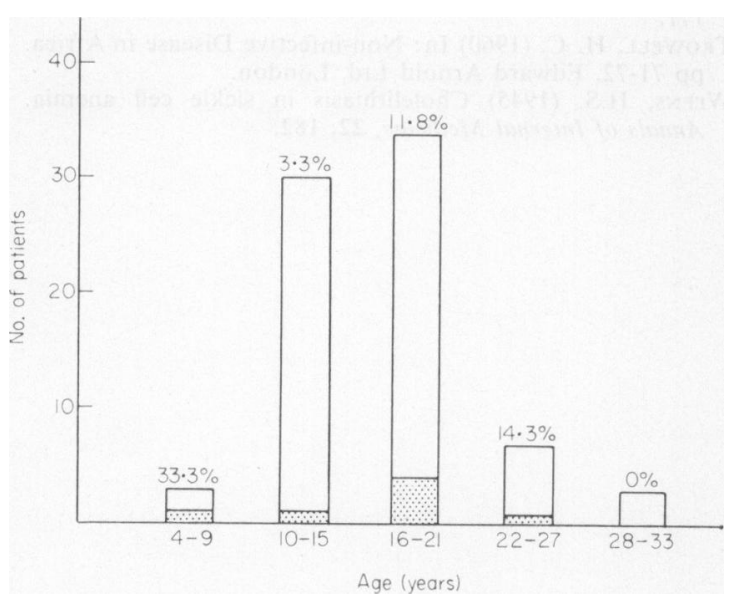

FIG. 1. Age distribution of 77 Nigerians with sicklecell disease (Hb S) examined for gall stones. $\square$ Without gall stones; with gall stones.

TABLE 1. Abdominal pain and cholelithiasis in homozygous sickle-cell disease in Lagos

\begin{tabular}{|c|c|c|c|}
\hline & $\begin{array}{l}\text { No. of patients } \\
\text { without stones }\end{array}$ & $\begin{array}{l}\text { No. of patients } \\
\text { with stones }\end{array}$ & ts Total \\
\hline $\begin{array}{l}\text { No. of patients with } \\
\text { abdominal pain } \\
\text { during previous }\end{array}$ & 70 & 7 & 77 \\
\hline 12 months & $8(11 \cdot 4 \%)$ & $2(28 \cdot 6 \%) \quad 1$ & $10(12.9 \%)$ \\
\hline
\end{tabular}

Although the relatively longer average life span of Americans with sickle-cell disease may contribute to the higher prevalence of gall stones in them, it cannot be the only explanation. This is partly because the stones are formed quite early in life and cholelithiasis has been reported in at least 6 Americans with SCD aged between 6 and 14 years (Weens, 1945; Mintz,
Church and Adams, 1955; Cameron et al., 1971; Jordan, 1971; Ariyan et al., 1976). Furthermore, the present authors' chart (Fig. 1) did not show a pattern of increasing incidence with age. The answer might be related to the fact that biliary tract disease is very rare in the general population of Nigeria. Da RochaAfodu and Adesola (1971) reported prevalences of $0.18 \%$ for cholelithiasis and of $0.3 \%$ for cholecystitis from 5529 post-mortems in Lagos. They are also supposedly rare in all African races (Trowell, 1960; Edington and Gilles, 1969). This rarity may be related to some dietary habits such as the low consumption of refined fibre-depleted foods by most Africans (Heaton, 1977) and is apparently reflected also in the low prevalence in Nigerians with SCD. This dietary factor is likely to be relevant as the prevalence of cholelithiasis has increased dramatically over the last 60 years in Afro-Americans and Canadian Eskimos as they have eaten more 'Western' refined carbohydrate and low-fibre diets (Heaton, 1977).

A high incidence of cholelithiasis up to $70 \%$ is known to be associated with congenital haemolytic anaemias and its resultant hyperbilirubinaemia (Mayo, 1929). The latter is a possible mechanism for the cholelithiasis in SCD, but in the absence of evidence of greater haemolysis in Americans than in Nigerians, other factors such as dietary habits prevalent in the general population would appear to contribute to it.

The lack of radiographic evidence of cholelithiasis in the only patient with signs and symptoms suggesting its presence may have been due to the passage of the stones into the duodenum as has been described by Cameron et al. (1971) and Ariyan et al. (1976).

In patients without haemoglobinopathy, Lund (1960) has shown that up to $50 \%$ of all patients with asymptomatic cholelithiasis subsequently develop severe symptoms or complications and at least $2.7 \%$ of them die from it if followed-up for as long as 20 years. Since the mortality of elective cholecystectomy was less than $1 \%$ he argues strongly for this procedure in all cases in order to prevent future morbidity and mortality. Although the contribution of biliary tract disease to the abdominal symptoms in SCD remains controversial, many authors have described their occurrence but are divided on the value of prophylactic elective cholecystectomy in these patients (Barrett-Connor, 1968; Cameron et al., 1971 ; Golding et al., 1973; Ariyan et al., 1976). Most of them, however, favour the operation because there is no evidence of increased operative mortality if the patients are well managed. So far in West Africa, this operation has not been seriously considered because of the rarity of biliary tract disease and of symptoms attributable to it. Increasing 
longevity of patients due to better management and increasing awareness of the diagnosis among doctors will undoubtedly increase the instances of difficult decisions about cholecystectomy.

\section{Acknowledgments}

We are grateful to the staff of the Haematology Unit, the Departments of Radiodiagnosis and of Medical Illustration and to Mrs M. O. Olorunnisomo, all of the College of Medicine and the Lagos University Teaching Hospital, for valuable assistance.

\section{References}

Ariyan, S., Shessei, F.S. \& Pickett, L.K. (1976) Cholecystitis and cholelithiasis masking as abdominal crises in sickle cell disease. Pediatrics, 58, 252.

BARRETT-CONNOR, E. (1968) Cholelithiasis in sickle cell anemia. American Journal of Medicine, 45, 889.

Cameron, J.L., Maddrey, W.C. \& Zuidema, G.D. (1971) Biliary tract disease in sickle cell anemia: Surgical considerations. Annals of Surgery, 174, 702.
DA Rocha-Afodu, J.T. \& Adesola, A.O. (1971) Cholecystitis in Nigerians. Journal of the Nigerian Medical Association, 1, 47.

Edington, G.M. \& Gilles, H.M. (1969) In: Pathology in the Tropics. pp. 386 and 514. Edward Arnold Ltd, London.

Golding, T.N., Adeyemo, A. \& Kurtz (1973) The incidence and surgical significance of cholelithiasis in sickle cell anemia and sickle cell trait. Journal of the National Medical Association, 65, 410.

Heaton, K.W. (1977) In: Recent Advances in Medicine No. 17 (Ed. by Baron, D.N., Compston, M. \& Dawson, A.M.), p. 323. Churchill Livingstone, Edinburgh.

JORDAN Jr, G.L. (1971) Biliary tract disease in sickle-cell anemia. Annals of Surgery, 174, 710.

LUND, J. (1960) Surgical indications in cholelithiasis: Prophylactic cholecystectomy elucidated on the basis of longterm follow up on 526 monoperated cases. Annals of Surgery, 151, 153.

Mayo, W.J. (1929) Collected papers of the Mayo Clinic, 11, 63.

Mintz, A.A., Church G., \& Adams, E.D. (1955) Cholelithiasis in sickle-cell anemia. Journal of Pediatrics, 47 171.

Trowell, H. C. (1960) In: Non-infective Disease in Africa. pp 71-72. Edward Arnold Ltd, London.

WeENS, H.S. (1945) Cholelithiasis in sickle cell anemia. Annals of Internal Medicine, 22, 182. 


\section{CORRIGENDUM}

Postgraduate Medical Journal

June 1979 Vol. 55 No. 644

Page 400, paragraph 1 of right hand column, line 5:

for

presence of haemoglobin 5 (Hb 5) only, or with a

read

presence of typical symptoms and signs, anaemia, 